\title{
Effect of species identity and diversity on biomass production and its stability in cover crop mixtures
}

\author{
Marina Wendling $^{\mathrm{a}, \mathrm{b}, *}$, Raphaël Charles ${ }^{\mathrm{b}}$, Juan Herrera ${ }^{\mathrm{a}}$, Camille Amossé ${ }^{\mathrm{a}}$, Bernard Jeangros ${ }^{\mathrm{a}}$, \\ Achim Walter ${ }^{\mathrm{c}}$, Lucie Büchi ${ }^{\mathrm{a}} \mathrm{d}$ \\ ${ }^{a}$ Agroscope, Plant Production Systems, Nyon, Switzerland \\ ${ }^{\mathrm{b}}$ FiBL, Research Institute of Organic Agriculture, Lausanne, Switzerland \\ ${ }^{\mathrm{c}}$ ETH Zurich, Institute of Agricultural Sciences, Zürich, Switzerland \\ ${ }^{\mathrm{d}}$ Natural Resources Institute, University of Greenwich, Chatham, United Kingdom
}

\section{A R T I C L E I N F O}

\section{Keywords:}

Complementarity effect

Growing conditions

Interspecific interactions

Overyielding

Risk of failure

Simplex design

\begin{abstract}
A B S T R A C T
Thanks to positive interactions between species, growing mixtures of cover crops allows improving the ecosystem services provided by cover crop cultivation. In this study, the influence of species diversity but also of species identity and mixture composition on cover crop biomass production and its stability in diverse growing conditions was studied. Several field experiments (varying soil type, preceding crop, soil tillage, sowing density, nitrogen fertilization and spatial replication) were set up in Switzerland during the period 2013-2016. In these experiments, the performance of cover crop species grown as sole crops was compared to that of multispecific mixtures. Part of these experiments followed a simplex design in which four cover crop species were combined together with different proportions, producing a total of 25 mixtures of varied diversity. The other experiments compared sole crop and mixture biomass production in standard randomised block or split plot experiments.

Globally, mixtures tended to produce slightly more biomass than the sole crops, with an average between $2 \mathrm{t} /$ ha and $3.2 \mathrm{t} /$ ha for sole crops and of about $3.5 \mathrm{t} /$ ha for mixtures. Overyielding as well as transgressive overyielding were observed, in $81 \%$ and $37 \%$ of the cases on average, respectively. However no effect of the level of species diversity within mixtures could be found. Biomass production of cover crops was highly influenced by their growing conditions and by the identity of the species involved, especially for sole crops and bispecific mixtures. The analyses of the simplex experiments allowed to show that species interactions played an important role in biomass production in 7 out of 15 growing conditions, even for a short growing period of about three months. Most of the cover crop mixtures with the highest biomass production had a rather low diversity, i.e. about two species on average, but the identity of the species involved in these mixtures depended on the growing conditions. Our results do not show a strong diversity effect on the biomass production of cover crop mixtures cultivated for a short growing period, but a stronger effect of species identity and of the growing conditions. Mixtures with low diversity generally outcompete more diverse mixtures, but more diverse mixtures offer an insurance effect given the unpredictability of growing conditions during cover crop cultivation.
\end{abstract}

\section{Introduction}

Cover crops are cultivated between main crops to provide ecosystem services such as soil protection, weed control or nutrient recycling. Currently, there is a strengthened interest in growing mixtures instead of sole crops as mixtures allow to improve the services provided by cover crops. Several studies conducted in natural ecosystems (Hooper et al., 2005) and intercropping (e.g. Andersen et al., 2004; Bedoussac and Justes, 2010; Hauggaard-Nielsen et al., 2006) showed that the performance of a mixture can exceed the average of the individual performance due to positive interactions between species. This improved performance of mixtures, called diversity effect, can lead to higher biomass production (Cardinale et al., 2011). It is referred to as 'overyielding' when the mixture produces more than the average of sole crops (Schmid et al., 2008), and 'transgressive overyielding' when the mixture produces more than the best sole crop (Gravel et al. 2012). Overyielding and transgressive over [Gravel et al., 2012] yielding have been shown in grasslands (Kirwan et al., 2007; Nyfeler et al., 2009) and cover crops (Sainju et al., 2006; Tribouillois et al., 2016; Wang et al., 2012; Wendling et al., 2017). Positive effect of diversity could also lead

\footnotetext{
* Corresponding author at: FiBL, Research Institute of Organic Agriculture, Avenue des Jordils 3, CP 1080, 1001, Lausanne, Switzerland.

E-mail address: marina.wendling@fibl.org (M. Wendling).
} 
to higher stability in biomass production (Haughey et al., 2018; Tilman et al., 2006; Yachi and Loreau, 1999). It has been shown for example that, for a broad range of extreme climate events, high-diversity communities (16-32 species) had higher productivity stability, i.e. the ability to perform similarly in normal and extreme climate events, than low-diversity communities (1-2 species) (Isbell et al., 2015). Nevertheless, the results of the studies investigating this diversity-stability relationship are contrasted. Several studies revealed no clear advantage of increasing the number of species in terms of yield stability in mixtures of few species (up to 7 species) (Sanderson, 2010; Miyazawa et al., 2014).

Three main mechanisms induce the positive effects of diversity: resource complementarity, facilitation and sampling effect. Resource complementarity occurs when species differ in their resource requirements, resulting in a more efficient resource use by mixtures than sole crops (Fridley, 2001). Complementarity has been largely reported for nitrogen $(\mathrm{N})$ in mixtures associating legumes, which biologically fix atmospheric $\mathrm{N}$, and other species, which have only access to soil $\mathrm{N}$ (e.g. Hauggaard-Nielsen et al., 2001). Complementarity also occurs for other resources, such as light (Spehn et al., 2000). Facilitation corresponds to a positive interaction between two species resulting directly and indirectly 'from the modifications of biotic or abiotic conditions' (McIntire and Fajardo, 2014). Five mechanisms of facilitation have been identified: stress amelioration, novel habitat creation, creation of habitat complexity, access to resources and service sharing. Besides complementarity and facilitation, the sampling effect corresponds to the greater probability of a mixture associating a large number of species to contain at least one species adapted to a particular environment and thus performing well (Loreau and Hector, 2001). This species will compensate for the low yield of less adapted species, providing stability to the mixture. Another major driver of stability is the asynchrony in species responses to environmental fluctuations (Yachi and Loreau, 1999; Sasaki et al., 2019). To better understand the effects of species diversity, it is essential to disentangle the different mechanisms involved (Barry et al., 2018).

Contrary to grassland systems, studies on diversity effects in cover crop mixtures are much more limited and often focused on bispecific mixtures (e.g. Hayden et al., 2014; Wendling et al., 2017). Nevertheless, as most of the services provided by cover crops are driven by their biomass production, it is essential to understand the effect of diversity on biomass production of cover crop mixtures. Kirwan et al. (2009) developed a modelling framework based on a simplex design (Cornell, 2002), in which the effects of species identity and diversity on ecosystem function can be assessed. This modelling framework has been largely used in grasslands to understand the higher performance of mixtures compared to sole crops in terms of biomass production and $\mathrm{N}$ uptake (Nyfeler et al., 2009; Sturludóttir et al., 2014; Husse et al., 2016). However, this methodology has never been applied on cover crop mixtures or on communities with very short growing period.

Besides the target of high biomass production, stability is also a key element of cover crop success. Cover crops are generally grown in summer during a short period and need to achieve high biomass very quickly. However, growing conditions, especially soil moisture and nutrient availability, can be highly variable during summer. It is thus crucial to identify species or mixtures that are adapted to a wide range of pedoclimatic conditions to ensure a good performance. The studies investigating stability of cover crops (Wortman et al., 2012; Smith et al., 2014) have shown that mixtures had comparable or even lower stability than sole crops, but these studies considered a limited number of growing conditions (mostly two). It is thus important to assess the influence of species diversity on biomass production and stability in a large range of contrasting growing conditions. The identity of the species involved in the mixture composition also needs to be considered next to the diversity of mixtures since the three mechanisms described above and involved in the diversity effect all rely on species-specific characteristics (Callaway, 1998; Choler et al., 2001). Species identity is often neglected in studies on diversity effects (Díaz and Cabido, 2001). Finally, the measure used to appraise stability in biomass production should be carefully chosen. In cover crop or natural systems, stability is mostly assessed using the coefficient of variation (CV, ratio of standard deviation of the yield to its mean) or its inverse 1/CV (e.g. Tilman et al., 2006; Wortman et al., 2012) even though its limitations have been recognized by several studies (e.g. Steudel et al., 2011; Carnus et al., 2015). Basing crop choice only on the CV values can lead to misleading conclusions as it does not allow to separate the response of the mean from its variability. In agricultural systems when comparing different species or mixtures in contrasted growing conditions, the smallest CV, indicating the highest stability with the smallest variation around the mean, may not necessarily be the desired option as it can be associated to lower-yielding crops. To face the lack of information of the $\mathrm{CV}$, several studies have considered both the mean and the variation of the response (e.g. Haughey et al., 2018). Another option would be to assess stability in its dynamic view (as opposed to the static view with the CV), using linear regression method as described by Finlay and Wilkinson (1963). This method assesses species response to the growing conditions.

The main objectives of this study were i) to investigate the effect of diversity on cover crop biomass production and its stability; ii) to determine the relative role of species identity and diversity on biomass production and stability iii) to assess the effect of diversity and identity in different growing conditions. Here we define 'diversity effect' as the difference between the performance of mixtures compared to the average of monocultures (also named 'overyielding' when the difference is positive, Schmid et al., 2008), and 'identity effect' as the difference in performance of mixtures with the same diversity in the same growing conditions, arising from the identity of the species included in the mixtures (Kirwan et al., 2009). 'Mixture composition' refers to the specific set of species included in the mixture. To address these objectives, a simplex design experiment was carried out in four consecutive years (2013-2016) in Switzerland, in different growing conditions. Additional field experiments conducted in the same site during the same years were used to compare biomass production and its stability in sole crops vs mixtures.

\section{Materials and methods}

\subsection{Field experiments}

The study was carried out at the research station of Agroscope in Changins ( $46^{\circ} 23^{\prime} 59.3^{\prime \prime} \mathrm{N} 6^{\circ} 14^{\prime} 20.2^{\prime \prime} \mathrm{E}, 426 \mathrm{~m}$ asl), Switzerland, where the average total annual precipitation is $999 \mathrm{~mm}$ and the mean temperature $10.2^{\circ} \mathrm{C}$ (30-year averages, $\left.1981-2010\right)$.

\subsubsection{Multi years standard design: sole crops versus mixtures}

In order to compare mixtures to sole crops and to assess the effect of diversity across contrasting growing conditions, several experiments have been conducted from 2013 to 2016, in different fields of the research station. These experiments consisted in several cover crop species sown as sole crop or in mixtures, and differed in terms of years, soil types, preceding crops and cropping practices (soil tillage, sowing density, $\mathrm{N}$ fertilisation, spatial replication). Each single combination of these factors was considered as one growing condition. Some of the experiments included replicates. A schematic description of the concept of growing conditions is given in Figure S1. A first series of experiments compared an 11 -species mixture (50\% of legumes and $50 \%$ of other species, Table S1) and six sole crops (Indian mustard Brassica juncea, field pea Pisum sativum, black oat Avena strigosa, phacelia Phacelia tanacetifolia, niger Guizotia abyssinica and daikon radish Raphanus sativus longipinnatus), grown in 72 growing conditions ('Mix 11 ' dataset). The second series of experiments compared a 4-species mixture together 
with its four species components in 36 different growing conditions ('Mix4' dataset). The 4-species mixture was composed of Indian mustard, field pea, black oat and phacelia sown in equal proportion ( $25 \%$ of the respective standard sowing density, Table S1). A detailed description of the different experiments in terms of year, preceding crop, soil type, weather conditions and cropping practices is given in Table S2.

Cover crops were sown between $2 \mathrm{~cm}-4 \mathrm{~cm}$ depth in microplots ranging between $10 \mathrm{~m}^{2}-26.25 \mathrm{~m}^{2}$ between the end of July and the beginning of August using an experimental seeder.

Cover crop cultivars and standard targeted sowing densities are given in Table S1. Depending on the growing conditions, the preceding crop was alfalfa, winter wheat or winter barley. Soil tillage before cover crop seeding ranged from plough followed by rotary harrow to minimal tillage with rotary harrow only or direct seeding. Cover crop dry matter production was assessed between 53 and 98 days after sowing (DAS) by harvesting aboveground parts at the ground level from $0.5 \mathrm{~m}^{2}$ per plot (two $0.5 \times 0.5 \mathrm{~m}$ quadrats representative of the plot). The samples were dried for $72 \mathrm{~h}$ at $55^{\circ} \mathrm{C}$ and weighed. A more detailed description of the growing conditions and cover crop management practices in each growing condition is given in Table $\mathrm{S} 2$.

\subsubsection{Multi years simplex design: mixtures with different species proportion and diversity}

In order to investigate more deeply the influence of species identity and diversity on biomass production, a field experiment was conducted four consecutive years (2013-2016), in different fields on the same site. The experiments were conducted with four species, field pea, Indian mustard, black oat and phacelia. These species have been chosen for their complementarity. It has been evidenced that they present very different functional traits relevant for several ecosystemic services (Tribouillois et al., 2015). These species differ also in terms of their root system and nutrient acquisition strategy (Wendling et al., 2016) and in terms of competitive ability (Wendling et al., 2017). Following a simplex design (Kirwan et al., 2009), the four species were combined with different sowing densities resulting in 25 different mixtures of varying diversity. These 25 combinations included the four sole crops $(100 \%$ of the standard density, see below), six bispecific mixtures (50\% of two species), four 3-species mixtures (33\% of three species) and eleven 4 species mixtures. The 4 -species mixtures consisted of equal stands $(25 \%$ of each species, effective diversity $=4$, see 2.2 .2 for the computation of effective diversity), dominant stands $(70 \%$ of one species and $10 \%$ of the three others, effective diversity $=2.6$ ) and co-dominant stands ( $40 \%$ of two species and $10 \%$ of the two others, effective diversity $=$ 3.3). In 2013, the experiment was carried out without $\mathrm{N}$ fertilisation, with a standard sowing density (given below), and was replicated (three replicates). In 2014, 2015 and 2016, the experiment was conducted without replicates (which are not necessary for this type of design) with two sowing density levels (standard: 100\% and low: 50\% of the sowing densities given below) and two $\mathrm{N}$ fertilisation levels ( $0 \mathrm{~kg}$ $/ \mathrm{ha}^{-1}$ and $30 \mathrm{~kg} / \mathrm{ha}$ ). A total of 15 growing conditions differing by year, sowing density, $\mathrm{N}$ fertilisation and replicate were thus produced ('Simplex' dataset). Cover crops were sown at $2 \mathrm{~cm}$ depth in $10 \mathrm{~m}^{2}$ plots between end of July and beginning of August using an experimental seeder with $13.5 \mathrm{~cm}$ row spacing. The standard targeted sowing densities were $500 \mathrm{pl} / \mathrm{m}^{2}$ for mustard and phacelia, $150 \mathrm{pl} / \mathrm{m}^{2}$ for pea and $400 \mathrm{pl} / \mathrm{m}^{2}$ for oat. The preceding crop was alfalfa in 2013 , winter wheat in 2014 and 2016, and winter barley in 2015. In 2013 and in 2015, the soil was ploughed and harrowed before cover crop seeding, while it was only harrowed in 2014 and in 2016. Irrigation was applied in 2013 ( $15 \mathrm{~mm}$ at 7 and 9 DAS) and in 2016 (20 mm at 23 DAS) to insure cover crop emergence. Ammonium nitrate was applied at the beginning of the growing period (between 1 and 12 DAS) on the fertilised plots. Cover crop dry matter production was assessed about 70 DAS as described in 2.1.1. Growing conditions and cover crop management practices are described more deeply in Table S3.

\subsection{Data analysis}

\subsubsection{Biomass production, stability and risk of failure}

The biomass production of sole crops vs mixtures was compared using analyses of variance. In the Simplex dataset, the influence of effective diversity in cover crop mixtures on biomass production, stability in biomass production and risk of failure was assessed by a linear regression:

$y=a \times x+b$

where $y$ represents the response variable, either biomass production, stability in biomass production or risk of failure. $x$ corresponds to the explanatory variable, i.e. the effective diversity.

In order to evaluate the contribution of species diversity, identity and growing conditions to cover crop biomass production, a linear mixed-effect model was adjusted using the function 'lmer' of the $\mathrm{R}$ package 'Ime4' (Bates et al., 2015) with species diversity, identity and growing conditions as random factors. The influence of the growing conditions on cover crop biomass production was composed of the effect of the year (weather conditions) and of the intra-year effect combining soil type and cropping practices.

Stability of biomass production was assessed using two concepts of stability, static and dynamic stability. First, according to the static concept, the coefficient of variation (CV) of biomass across growing conditions for each cover crop species and mixture was computed. A low CV indicates a stable production, i.e. a production which does not vary much in different growing conditions. Second, an evaluation of cover crop response to the growing conditions using the linear regression method proposed by Finlay and Wilkinson (1963), a dynamic view of stability, was performed. For this method, the average biomass production of all cover crops grown in one growing condition was used to characterise the productivity of this growing condition. Growing conditions were then ordered from the lowest to the highest productivity. Then, for each growing condition, the difference between the biomass of a particular cover crop (sole crop or mixture) and the productivity of the growing condition was computed. For each cover crop, a linear regression of this biomass difference on the productivity of the growing conditions was adjusted. Cover crop biomass production stability was then assessed by the slope of the linear regression. Cover crops having a slope not significantly different from zero are considered as 'dynamically' stable as they follow the general increase of productivity. To distinguish this stability from the static concept given by the $\mathrm{CV}$, this stability coefficient will be discussed using the term of 'responsiveness'. A positive slope indicates that the cover crop is responsive to the growing conditions, but less stable in the static concept. A negative slope corresponds to a lower response to the growing conditions, meaning that species biomass increase is lower than the increase in productivity of the growing conditions, or to a negative response. In addition, for each cover crop, a 'risk of failure', defined as the probability of producing less than $3 \mathrm{t} / \mathrm{ha}$ of biomass, was estimated. This threshold of $3 \mathrm{t} /$ ha corresponds to the minimal biomass that should be produced to provide the services expected from cover crops (e.g. weed control, Gebhard et al., 2013; Gfeller et al., 2018). Cover crop biomass production was computed for 10,000 randomly generated productivity values, using the coefficients of their linear regression. The productivity of the growing conditions was assumed to follow a Gaussian distribution (mean $=3 \mathrm{t} / \mathrm{ha}$, standard deviation $=1.5 \mathrm{t} / \mathrm{ha}$ ). The mean and standard deviation of the productivity of the growing conditions were assessed after an analysis of 73 cover crop experiments conducted in Switzerland. The risk of failure was then computed by the ratio of biomass values lower than $3 \mathrm{t} /$ ha on the total number of values simulated.

\subsubsection{Identity and diversity effect in simplex design}

The effect of species identity and interactions on mixture biomass production were assessed for each growing condition by linear models 
following the modelling framework developed by Kirwan et al. (2009). This method compares a series of six models, based on different ecological assumptions about species interactions, with different levels of complexity. All the models tested are presented in Table S4. The simplest model, the null model, assumes that all the species produce the same biomass and do not interact, while the most complex model includes the effect of species identity and pairwise interactions (Model 5 of Table S4). In addition, one model based on a functional approach was tested and compared to the models based on species identity. It compared the effect of the legume species (i.e. pea) with that of the non-legume species (i.e. mustard, oat and phacelia), together with a potential interaction between these two groups. The comparison of the different models, starting from the simplest one, permits the selection of the best fitting model and the identification of the factors (species identity and interaction effects) influencing biomass production. Each of these models was adjusted on the data of each of the 15 growing conditions of the Simplex dataset. In 2013, the model adjustment was made independently and jointly on the three replicates together to increase robustness. The models were simplified to keep only significant terms. The models were then compared, and the best fitting model was selected using an $F$ test $(\mathrm{p}<0.05)$. For the best model in each growing condition, the combination of species proportion producing the highest biomass was determined. However, as different combinations could lead to really similar biomass production, all the combinations producing more than $95 \%$ of the highest possible biomass were retained. The species effective diversity (Jost, 2007) corresponding to each of these combinations was estimated as:

$D=\exp \left(-\sum_{i=1}^{S} p_{i} \times \ln P_{i}\right)$

where $P_{i}$ is the relative proportion of species $i$, and $S$ is the number of species in the mixture. Effective diversity corresponds to the number of species in equal proportion needed to produce the same diversity as that observed.
For each best combination, the part of biomass resulting from species identity effect and from interactions, i.e. diversity effect, were determined. 2018).

All statistical analyses were performed with R 3.5.1 (R Core Team,

\section{Results}

3.1. Effect of diversity on cover crop biomass production, stability and risk of failure

For each year, average daily temperature was around $20^{\circ} \mathrm{C}$ at the beginning of the cover crop growth and decreased progressively to reach about $10^{\circ} \mathrm{C}$ at harvest date. Between cover crop seeding (around August $1 \mathrm{st}$ ) and biomass sampling (around the 15th of October), the mean temperature was similar each year, around $17{ }^{\circ} \mathrm{C}\left(17.2^{\circ} \mathrm{C}, 17.1^{\circ} \mathrm{C}\right.$, $16.8^{\circ} \mathrm{C}$ and $17.7^{\circ} \mathrm{C}$ in $2013,2014,2015$ and 2016). The different years had also quite similar growing degree days (GDD, with a base temperature of $\left.10^{\circ} \mathrm{C}\right), 559,542,526$ and 595 GDD respectively. In contrast, the amount of rainfall over this period changed drastically between years. While it was around $250 \mathrm{~mm}$ in the three first years $(247 \mathrm{~mm}$, $224 \mathrm{~mm}, 284 \mathrm{~mm}$ in 2013, 2014 and 2015), it reached only $94 \mathrm{~mm}$ in 2016.

Over all cover crops and growing conditions, biomass production was highly variable ranging from less than $1 \mathrm{t} /$ ha to about $7 \mathrm{t} / \mathrm{ha}$ with an average between $2 \mathrm{t} / \mathrm{ha}$ and $3.2 \mathrm{t} /$ ha for sole crops and of about $3.5 \mathrm{t} /$ ha for mixtures (Fig. 1a -1c). Globally, cover crop mixtures showed a slightly higher biomass than sole crops in two out of three datasets (Fig. 1a, Mix11: $\mathrm{p}=0.004$, Fig. 1b, Mix4: $\mathrm{p}=0.195$ and Fig. 1c, Simplex: $p=0.036$ ). However, when comparing mixtures of different diversity level (between 2 and 4 species), no effect of species diversity was observed (Fig. 1d, Simplex: $\mathrm{p}=0.43$ ). In Mix11, the mixture (11 species) exhibited overyielding (higher biomass than the sole crop average) in $90 \%$ of the cases (65 over 72 ) and transgressive
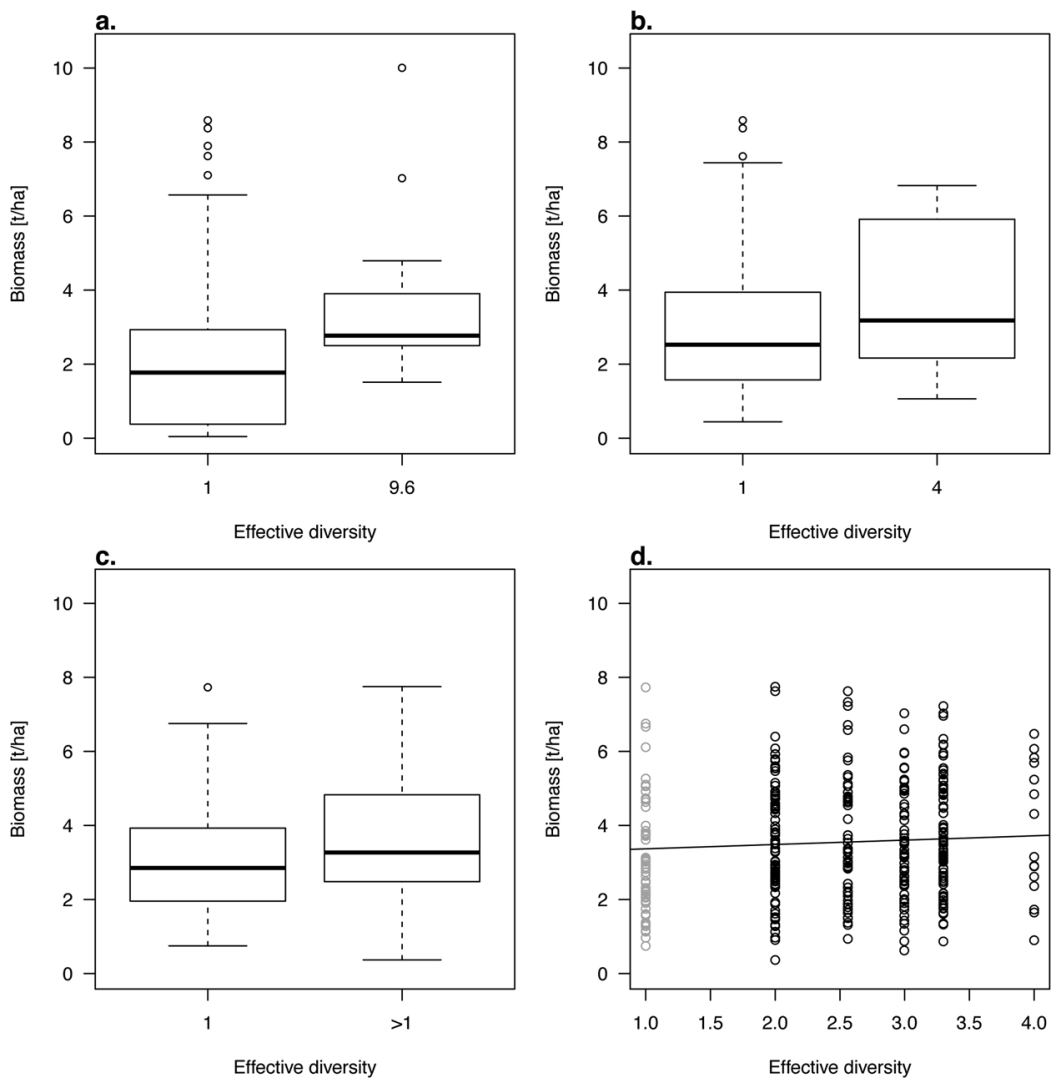

Fig. 1. Biomass production as a function of species diversity in Mix11 (a.), Mix4 (b.) and Simplex (c. and d.) datasets. The linear regression in d. was adjusted on mixtures only, its slope is not and b) and Mix4 (c and d). a and c) and of the sole crops (b and dLinear regressions of the difference between the biomass of a particular cover crop (sole crop or mixture) and the average of all cover crops on growing condition productivity in Mix11 (a and b) and Mix4 ( $\mathrm{c}$ and d). a and c linear regressions of sole crops and b and d linear regressions of mixtures. Significant slopes or intercepts are indicated with solid black lines, non-significant with solid grey lines.Grey points and dotted lines are shown to ease the comparison of panels a and $\mathrm{b}$, and $\mathrm{c}$ and $\mathrm{d}$. 
overyielding (higher biomass than the highest sole crop) in $50 \%$ of the cases (36 over 72). In Mix4, the mixture (4 species) exhibited overyielding in $83 \%$ of the cases (30 over 36 ) and transgressive overyielding in $31 \%$ of the cases (11 over 36 ). In Simplex, when analysing together the 21 mixtures, overyielding was observed in $69 \%$ of the cases, and transgressive overyielding in $30 \%$. The proportion of mixtures exhibiting overyielding did not differ significantly between each level of diversity.

The low effect of diversity can be partly explained by the high variability in biomass production linked to the identity of sole crops and mixture composition ('identity effect') and to the growing conditions in which the cover crops were grown. Indeed, the assessment of the relative contribution of cover crop diversity, identity and growing conditions (year on one side and soil and cropping practices on the other side) to the variation in biomass production showed that diversity explained about $3.7 \%$ of variability in biomass production (Mix $11: 11 \%$, Mix4: $0 \%$ and Simplex: 1\%). The identity effect contributed to about $3.6 \%$ of production variability (Mix11: 3\%, Mix4: 5\% and Simplex: $3 \%$ ), whereas the growing conditions accounted for about $64.8 \%$ (Mix11: 70\%, Mix 4: 55\% and Simplex: 69\%). The year alone explained $60.3 \%$ of the variation in biomass production (Mix11: 70\%, Mix 4: $55 \%$ and Simplex: 56\%). A large proportion of biomass variation (27.8\%) remained unexplained (Mix11: 16\%, Mix4: 40\% and Simplex: 27\%).

Species diversity did not influence the stability of biomass production, assessed through the coefficient of variation $(\mathrm{CV}, \mathrm{p}=0.693)$ and its responsiveness, measured by the slope of the linear regression $(\mathrm{p}=0.894)$. Moreover, no effect of diversity was observed on the risk of failure, i.e. probability of producing less than $3 \mathrm{t} / \mathrm{ha}(\mathrm{p}=0.216)$.

\subsection{Effect of species identity on cover crop biomass production, stability and risk of failure}

The influence of species identity and mixture composition on biomass production and stability was investigated across the different levels of diversity and growing conditions in the three datasets. Among sole crops, contrasted responses to growing conditions were observed
(Figs. 2 and 3). Compared to low-yielding growing conditions, field pea biomass production increased little in more favourable growing conditions resulting in the highest stability (responsiveness: slope between -0.52 and -0.81 , static stability: CV of about $30 \%$ ) but also the highest risk of failure (exceeding 80\%) (Tables 1 and 2).

By contrast, oat and niger responded more to growing conditions (slope $>0$ ) than the average of all cover crops (Fig. 2a and c and Fig. 3a, Tables 1 and 2). These species presented thus a highly variable biomass production (CV higher than $70 \%$ ) and had a lower risk of failure than pea (between $43 \%$ and $60 \%$ ). Mustard showed a similarly intense response to growing condition improvement to oat and niger in Mix11 and Mix4, with comparable CV and risk of failure (Fig. 2a and c, Table 1). In Simplex, mustard followed the general increase in productivity of the growing conditions (slope not different from 0 ) and had thus a risk of failure of $50 \%$ (Fig. 3a, Table 3). Phacelia also followed the general increase in productivity of the growing conditions but was slightly less productive than the average in Mix11 (0.7t/ha less, Table 1, Fig.2a). Phacelia exhibited a high CV, comparable to that of oat, niger and mustard and a risk of failure ranging from $50 \%$ to $68 \%$. The response to growing condition improvement of daikon radish was similar to that of phacelia, with a $0.7 \mathrm{t} /$ ha lower biomass production than the average of all cover crops (Table 1, Fig. 2a). In Mix11 and Mix4, the mixtures exhibited the lowest risk of failure $(20 \%$ and $36 \%$, respectively) and an intermediate $\mathrm{CV}$, between that of pea and that of oat (Tables 1 and 2).

The Simplex dataset, with a gradient of mixture diversity level, allowed to go deeper into the influence of diversity and identity effects in mixtures. Here, the influence of species identity depended highly on the diversity level (Fig. $3 \mathrm{~b}-\mathrm{f}$ ). For bispecific mixtures, species composition modified the performance of the mixture for 4 out of 6 mixtures. Two mixtures followed the productivity increase of the growing conditions but were either more productive (\#5: mustard-pea, $0.7 \mathrm{t} / \mathrm{ha}$ more) or less productive (\#8: pea-oat, $0.7 \mathrm{t} /$ ha less) than the average (Fig. $3 \mathrm{~b}$, Table 2). Mustard-pea showed thus a lower risk of failure than the average (32\%), while that of pea-oat was higher (69\%). For the two other bispecific mixtures, and a three-species mixture, a different
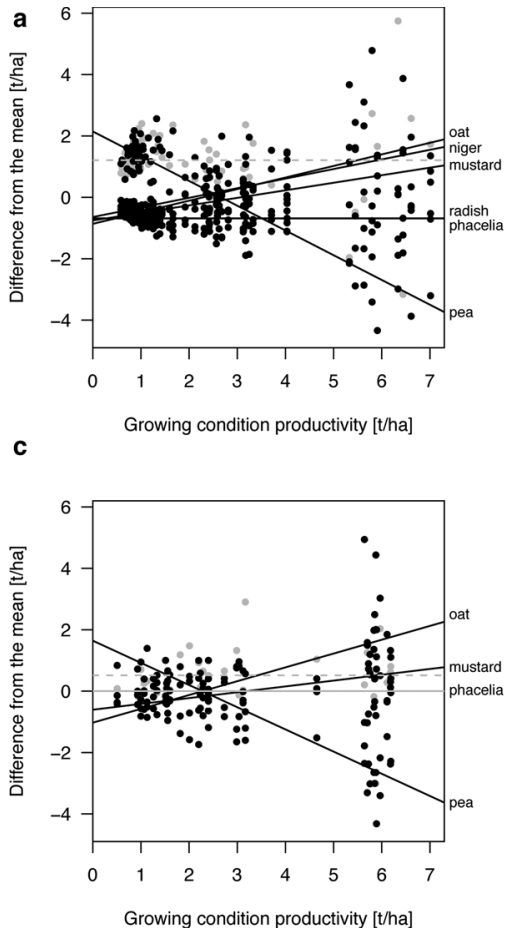

Growing condition productivity [t/ha]

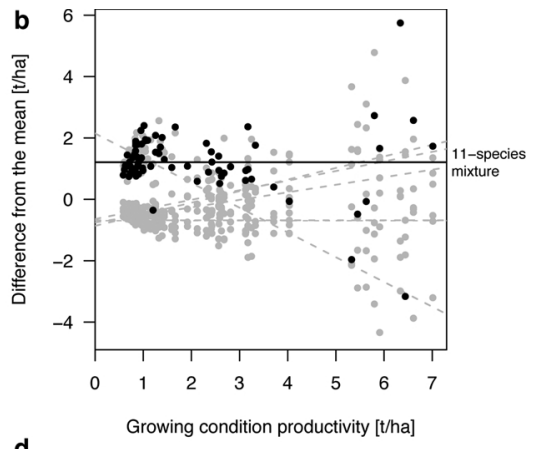

Fig. 2. Linear regressions of the difference between the biomass of a particular cover crop (sole crop or mixture) and the average of all cover crops on growing condition productivity in Mix11 (a and b) and Mix4 (c and d). a and c linear regressions of sole crops and b and d linear regressions of mixtures. Significant slopes or intercepts are indicated with solid black lines, non-significant with solid grey lines. Grey points and dotted lines are shown to ease the comparison of panels a and b, and $c$ and $d$.

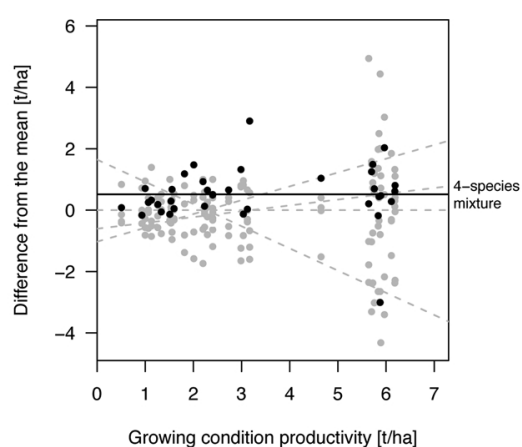



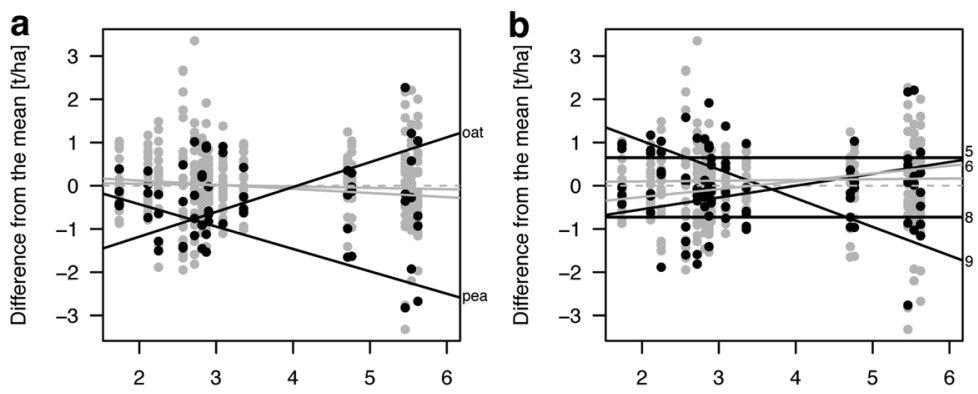

Growing condition productivity [t/ha]

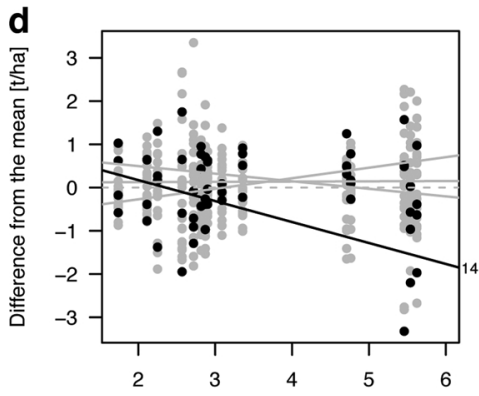

Growing condition productivity [t/ha]
Growing condition productivity [t/ha]

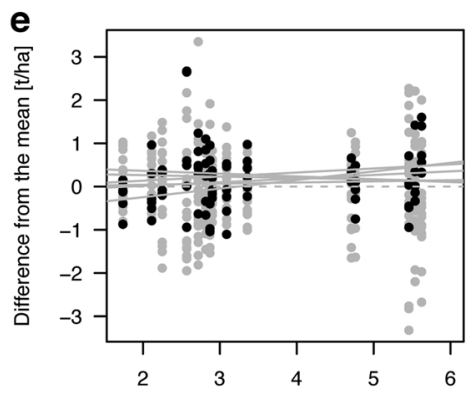

Growing condition productivity [t/ha]

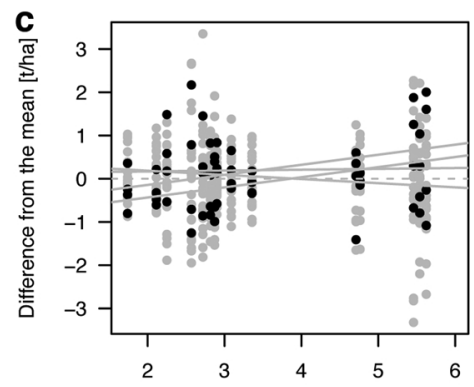

Growing condition productivity [t/ha]

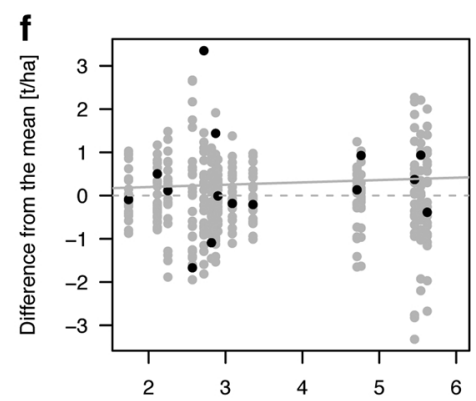

Growing condition productivity [t/ha]

Fig. 3. Linear regressions of the difference between the biomass of a particular cover crop (sole crop or mixture) and the average of all cover crops on growing condition productivity for the six diversity levels of Simplex dataset. Effective diversity is a. 1 species, b. 2 species, c. 2.6 species, d. 3 species, e. 3.3 species and f. 4 species. Significant slopes or intercepts are indicated with solid black lines, non-significant with solid grey lines. Numbers in the right margin correspond to the species combination number (see Table 2).

response to productivity improvement of the growing conditions was observed (Fig.3b and c). Pea-phacelia (\#9, Fig.3b) and pea-oat-phacelia (\#14, Fig. 3d) showed a negative slope, and mustard-oat (\#6, Fig.3b) a positive slope. Among these mixtures, pea-phacelia showed the lowest risk of failure (22\%) and the lowest CV (21\%). All other mixtures (16 out of 21), and thus especially all mixtures involving four species in varied proportion, showed an average response to growing conditions (slope and intercept not significantly different from 0 ), and species composition had no influence on mixture biomass production.

\subsection{Contribution of diversity and identity effects to cover crop biomass production in growing conditions with different productivity}

For each growing condition of the Simplex dataset, the best fitting model was determined to assess the importance of species identity and diversity in mixture biomass production and elucidate the patterns of interactions. The best model varied according to the growing conditions (Table 3 and Table S5). In the six poorest growing conditions except one, the best model was the null model, which assumes that all species perform identically and do not interact. Species identity has thus no influence on mixture performance, and all mixtures were predicted to produce the same biomass, whatever their species composition. In all other growing conditions (10 out of 15), mixture biomass production was affected by species identity and interactions (the interaction was significant in 7 cases and non-significant in 3 cases). Here the interactions involved were mostly pairwise interactions, but the species involved in the interactions differed between the growing conditions. Mixture performance was influenced by functional groups (legume vs non-legume species) in 3 cases ( 2 cases without interaction, 1 case with a significant interaction, Table 3$)$.

Table 1

Mean biomass production and coefficient of variation (CV) over all growing conditions, intercept and slope of the linear regressions of the difference between the biomass of a particular cover crop (sole crop or mixture) and the average of all cover crops on growing condition productivity, and probability of producing less than $3 \mathrm{t} / \mathrm{ha}$ (risk of failure) for each species and mixtures within Mix11 and Mix4 datasets .

\begin{tabular}{|c|c|c|c|c|c|c|c|c|c|c|c|c|c|c|}
\hline & \multicolumn{7}{|l|}{ Mix11 } & \multicolumn{7}{|l|}{ Mix4 } \\
\hline & $\begin{array}{l}\text { Mean biomass } \\
{[\mathrm{t} / \mathrm{ha}]}\end{array}$ & $\begin{array}{l}\mathrm{CV} \\
{[\%]}\end{array}$ & $\begin{array}{l}\text { Intercept } \\
\text { [t/ha] }\end{array}$ & p-value & Slope & p-value & $\begin{array}{l}\text { Risk of failure } \\
{[\%]}\end{array}$ & $\begin{array}{l}\text { Mean biomass } \\
{[\mathrm{t} / \mathrm{ha}]}\end{array}$ & $\begin{array}{l}\mathrm{CV} \\
{[\%]}\end{array}$ & $\begin{array}{l}\text { Intercept } \\
{[\mathrm{t} / \mathrm{ha}]}\end{array}$ & p-value & Slope & p-value & $\begin{array}{l}\text { Risk of failure } \\
{[\%]}\end{array}$ \\
\hline Fied pea & 2.56 & 27 & 2.15 & $<0.001$ & -0.81 & $<0.001$ & 83 & 2.56 & 33 & 1.64 & $<0.001$ & -0.72 & $<0.001$ & 89 \\
\hline Black oat & 2.11 & 121 & -0.86 & $<0.001$ & 0.38 & $<0.001$ & 44 & 3.78 & 82 & -1.03 & 0.006 & 0.45 & $<0.001$ & 43 \\
\hline Niger & 2.20 & 108 & -0.64 & $<0.001$ & 0.31 & $<0.001$ & 43 & - & - & - & & - & & - \\
\hline Indian mustard & 1.94 & 117 & -0.75 & $<0.001$ & 0.25 & $<0.001$ & 50 & 3.33 & 75 & -0.61 & 0.022 & 0.19 & 0.006 & 50 \\
\hline Phacelia & 1.47 & 127 & -0.70 & $<0.001$ & - & & 68 & 3.06 & 77 & - & & - & & 50 \\
\hline Daikon radish & 1.48 & 117 & -0.68 & $<0.001$ & - & & 67 & - & - & - & & - & & - \\
\hline 11-species mixture & 3.37 & 57 & 1.21 & $<0.000$ & - & & 20 & - & - & - & & - & & - \\
\hline 4-species mixture & - & - & - & & - & & - & 3.83 & 58 & 0.52 & 0.001 & - & & 36 \\
\hline
\end{tabular}


Table 2

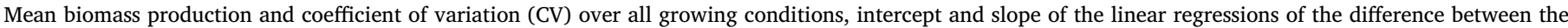

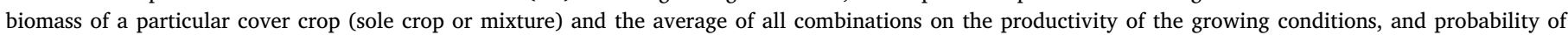
producing less than $3 \mathrm{t} / \mathrm{ha}$ (risk of failure) for the 25 combinations of the Simplex dataset.

\begin{tabular}{|c|c|c|c|c|c|c|c|c|c|c|c|c|c|}
\hline Type of cover crop & $\#$ & Effective diversity & $\begin{array}{l}\mathrm{Mu} \\
{[\%]}\end{array}$ & $\begin{array}{l}\mathrm{Pe} \\
{[\%]}\end{array}$ & $\begin{array}{l}\mathrm{Oa} \\
{[\%]}\end{array}$ & $\begin{array}{l}\mathrm{Ph} \\
{[\%]}\end{array}$ & $\begin{array}{l}\text { Mean biomass } \\
{[\mathrm{t} / \mathrm{ha}]}\end{array}$ & $\begin{array}{l}\mathrm{CV} \\
{[\%]}\end{array}$ & Intercept & $p$-value & Slope & p-value & $\begin{array}{l}\text { Risk of failure } \\
\text { [\%] }\end{array}$ \\
\hline \multirow[t]{4}{*}{ Sole crops } & 1 & 1.0 & 100 & - & - & - & 3.50 & 41 & - & & - & & 50 \\
\hline & 2 & 1.0 & - & 100 & - & - & 2.30 & 37 & 0.61 & 0.189 & -0.52 & $<0.001$ & 91 \\
\hline & 3 & 1.0 & - & - & 100 & - & 3.18 & 70 & -2.33 & 0.002 & 0.57 & 0.003 & 60 \\
\hline & 4 & 1.0 & - & - & - & 100 & 3.48 & 39 & - & & - & & 50 \\
\hline \multirow[t]{6}{*}{ 2-species } & 5 & 2.0 & 50 & 50 & - & - & 4.15 & 32 & 0.65 & 0.003 & - & & 32 \\
\hline & 6 & 2.0 & 50 & - & 50 & - & 3.37 & 53 & -1.09 & 0.030 & 0.27 & 0.040 & 55 \\
\hline & 7 & 2.0 & 50 & - & - & 50 & 3.51 & 51 & - & & - & & 50 \\
\hline & 8 & 2.0 & - & 50 & 50 & - & 2.77 & 57 & -0.73 & 0.001 & - & & 69 \\
\hline & 9 & 2.0 & - & 50 & - & 50 & 3.54 & 21 & 2.36 & 0.000 & -0.66 & $<0.001$ & 22 \\
\hline & 10 & 2.0 & - & - & 50 & 50 & 3.63 & 44 & - & & - & & 50 \\
\hline \multirow[t]{4}{*}{ 3-species } & 11 & 3.0 & 33 & 33 & 33 & - & 3.74 & 34 & - & & - & & 50 \\
\hline & 12 & 3.0 & 33 & 33 & - & 33 & 3.64 & 40 & - & & - & & 50 \\
\hline & 13 & 3.0 & 33 & - & 33 & 33 & 3.60 & 53 & - & & - & & 50 \\
\hline & 14 & 3.0 & - & 33 & 33 & 33 & 2.95 & 43 & 1.14 & 0.185 & -0.48 & 0.045 & 65 \\
\hline \multirow[t]{4}{*}{ 4-species } & 15 & 2.6 & 70 & 10 & 10 & 10 & 3.70 & 45 & - & & - & & 50 \\
\hline & 16 & 2.6 & 10 & 70 & 10 & 10 & 3.54 & 40 & - & & - & & 50 \\
\hline & 17 & 2.6 & 10 & 10 & 70 & 10 & 3.42 & 52 & - & & - & & 50 \\
\hline & 18 & 2.6 & 10 & 10 & 10 & 70 & 3.71 & 49 & - & & - & & 50 \\
\hline \multirow[t]{6}{*}{ 4-species } & 19 & 3.3 & 40 & 40 & 10 & 10 & 3.78 & 42 & - & & - & & 42 \\
\hline & 20 & 3.3 & 40 & 10 & 40 & 10 & 3.77 & 38 & - & & - & & 50 \\
\hline & 21 & 3.3 & 40 & 10 & 10 & 40 & 3.64 & 46 & - & & - & & 56 \\
\hline & 22 & 3.3 & 10 & 40 & 40 & 10 & 3.58 & 43 & - & & - & & 50 \\
\hline & 23 & 3.3 & 10 & 40 & 10 & 40 & 3.72 & 38 & - & & - & & 50 \\
\hline & 24 & 3.3 & 10 & 10 & 40 & 40 & 3.55 & 49 & - & & - & & 56 \\
\hline 4-species & 25 & 4.0 & 25 & 25 & 25 & 25 & 3.78 & 48 & - & & - & & 50 \\
\hline
\end{tabular}

\subsection{Diversity and composition of the most productive mixtures}

In the Simplex dataset, based on the best fitting models, the most productive combinations were determined in each growing condition (Table 3). When the best model is the null model, all combinations are equivalent and there is no most productive species combination. For the other cases, the diversity of the most productive combinations was relatively low in all growing conditions (about two species, Table 3). The best combinations were mostly bispecific mixtures including mainly mustard, pea and phacelia (e.g. growing condition 10, Fig. 4a). In growing condition 11, the best fitting model was that including the two functional groups (legume vs. non-legume species) with interaction, meaning that the highest achievable diversity is two. In these growing conditions, species diversity of the most productive combinations ranged between one and two (Fig. 4b). The model adjusted on the three replicates of 2013 (growing conditions 13-15) had the particularity that two types of species composition emerged among the best combinations (Fig. 4c). The first type included essentially the most productive sole crop, oat, and a lower variable proportion of mustard and phacelia. The second type associated mustard and pea. While being less productive than oat, these species interacted positively together, resulting almost in the same biomass production as that of oat alone.

Contrary to species diversity, which was always relatively low, we observed that species composition of these best performing combinations was highly dependent on the growing conditions (Fig. 4, Table S5). In most of these best combinations, about $20 \%$ of biomass production resulted from the interactions between species (i.e. diversity effect) (Table 3).

When looking at the raw Simplex data (biomass measured in the field, and not predicted with the models), the highest biomass was obtained with a bispecific mixture in 6 out of 15 growing conditions, and with a 2.6 diversity mixture in 3 growing conditions. Mixtures with 3 or 3.3 and 4 diversity were the most productive only in 5 growing conditions. Except for the mixture mustard-pea, which was the most productive in 5 growing conditions, all other best mixture compositions differed as a function of the growing conditions.

\section{Discussion}

4.1. Effect of species diversity and identity on biomass production and its stability

Overall, mixtures were slightly more productive than sole crops but no difference was observed on yield stability. While most studies investigating the influence of species diversity showed a positive correlation between diversity and biomass production or stability (Haughey et al., 2018; Hector et al., 2010; Isbell et al., 2009; Nyfeler et al., 2009), we did not observe that increasing species diversity in mixtures results in higher and more stable biomass yield. Two plausible explanations could be the varied influence of species identity according to diversity level, and the influence of the growing conditions.

Sole crop biomass production in different growing conditions and its stability was highly dependent on species identity. Field pea was the most productive sole crop in low-yielding growing conditions but it had a low response to growing condition improvement. Pea showed thus the highest yield stability resulting from the low yield potential of pea. Moreover, it has been shown that the capacity of legume species to rely on $\mathrm{N}$ fixation allows these species to be more productive than non-legume species in low-fertility conditions, where $\mathrm{N}$ is the most yieldlimiting factor (Askegaard and Eriksen, 2007). Contrary to pea, several species such as oat, niger or Indian mustard responded highly to the growing conditions. In favourable growing conditions, these species were able to produce more than $8 \mathrm{t} /$ ha of biomass in only 3 months of growth. By contrast, they were very little productive in poor growing conditions, highlighting that these species were selected for a fast growth in high-fertility growing conditions (Tribouillois et al., 2015). In 


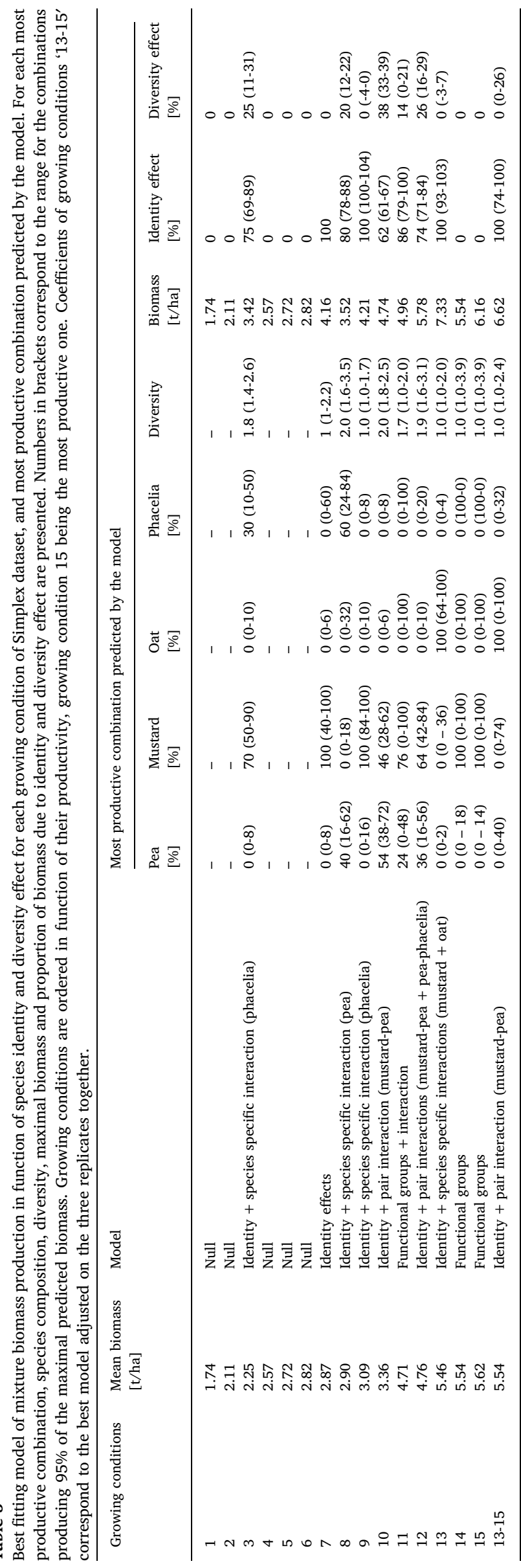

low-yielding growing conditions, yield of these productive species could be increased with fertilisation, as it was observed by HauggaardNielsen et al. (2008) for intercropped barley.

Biomass production and stability of bispecific mixtures were highly influenced by their species composition. For the same species at the same site, it has also been shown that mixture biomass production depended on the species involved due to differences in species competitive ability (Wendling et al., 2017). While facilitation effect were observed for pea and phacelia, mustard and oat had negative effects on the associated crop. Behind species specific competitiveness, many studies have reported the importance of functional differences between species for positive outcome of mixture performance (e.g. Tilman et al., 1997; Díaz and Cabido, 2001). Differences in functional traits have been evidenced by two studies for the four species tested here (Tribouillois et al., 2015; Wendling et al., 2016). These differences lead to complementarity between species, that has been largely evidenced for mixtures of legume and non-legume species (e.g. Jensen, 1996; Xiao et al., 2018). Compensatory interactions in mixtures, where the most competitive species overyields in mixtures and compensates for the less competitive one, are also an important ecological process for higher stability. It has been shown that compensatory interactions are even more important for mixture stability than complementarity between species (Creissen et al., 2016).

Contrary to bispecific mixtures, the performance of mixtures with higher diversity was not influenced by species composition. These mixtures showed similar responsiveness to the change in growing conditions and were as productive as the average of all cover crops. It has been reported that mixtures associating a large number of species with contrasting characteristics have a greater probability to contain at least one species adapted to a particular environment and thus performing well regardless of the growing conditions, this is called sampling effect (Loreau and Hector, 2001). However, while highly diverse mixtures will benefit from a high sampling effect, they will also have a lower yield advantage from the best adapted species compared to lowdiversity mixtures because of the lower sowing density of this species.

\subsection{Influence of the growing conditions on the diversity and identity effects}

Specific interactions were strongly influenced by the growing conditions. In the lowest yielding growing conditions, the best fitting model was the null model, meaning that species interactions were at best weak. Diversity effects had no significant influence on mixture biomass production in these growing conditions. This result contrasts with several experiments conducted in grassland systems, which evidenced that in poor fertility conditions, communities with high species diversity are more productive than communities with low diversity (Hooper et al., 2005). It is also in contradiction with several studies that showed that the contribution of facilitation is increased in stressful environments (Callaway et al., 2002; Pugnaire et al., 1996). However, whether or not the intensity of competition between species increases or is similar along productivity gradients is a long-standing debate in natural ecosystems (Goldberg and Novoplansky, 1997). Productivity gradients in natural or in agricultural systems are quite different and make the comparison difficult.

By contrast, mixture performance was influenced by species identity and diversity in intermediate and high-yielding growing conditions, resulting mostly in an increase in mixture biomass production with respect to sole crops. Contrary to Kirwan et al. (2007), we did not observe that the maximal diversity effect occurs when species are all in equal proportion ('evenness' model). In this study, in three cases, the best model included the functional groups 'legume' vs 'non-legumes', in which the specific identity of the non-legume species did not influence the estimated biomass production, as the three non-legume are interchangeable in this model. In most of the other growing conditions, the identity of the four species in the mixtures mattered, highlighting that other functional traits contributed to mixture performance. 

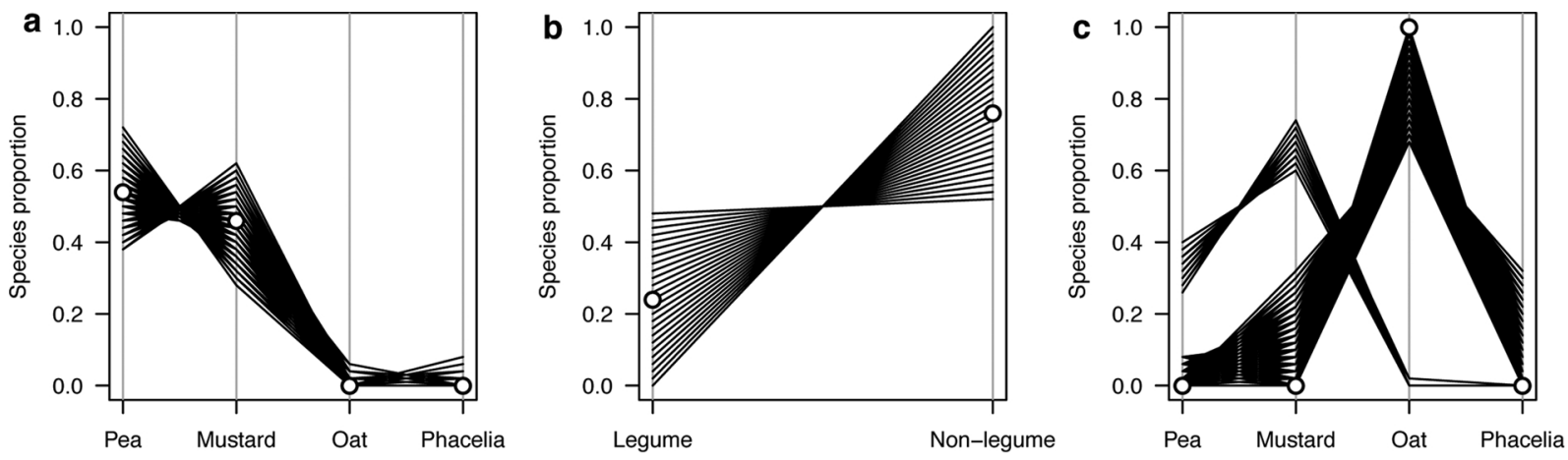

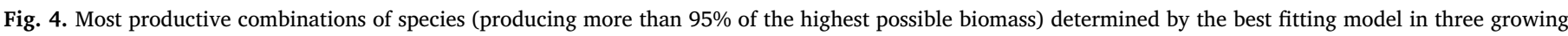

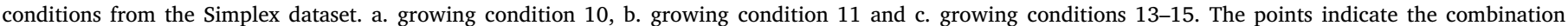
producing the highest biomass among these combinations.

In our study, the interactions were mostly pairwise interactions. The highest diversity effect occurred thus in bispecific mixtures with equal relative abundance of the two species involved in the interaction. This explains why we observed that the most productive cover crop was mostly a mixture with low diversity $(<2.6)$. Pairwise interactions are also an explanation to the higher variability in biomass production of bispecific mixtures in comparison to mixtures with high species diversity. Indeed, the diversity effect in bispecific mixtures with equal proportion of both species will be either high or null, depending on the species associated. By contrast, mixtures with a greater number of species have a higher probability of containing the species involved in the interaction, even if the diversity effect will be weaker due to lower sowing densities.

\subsection{Diversity and identity of the most productive mixtures in contrasting growing conditions}

Generally, in each growing condition, a species diversity as low as two species was sufficient to achieve the highest biomass. This has also been observed in grasslands where a few dominant and highly productive species determine the production of the community (Crawley et al., 1999; Rees et al., 2001). However, species composition of the best combination was highly variable and dependent on the growing conditions. The most productive combinations included mostly different species, present in different relative proportions. This result highlights the necessity of more complex mixtures that have lower yield variability than bispecific mixtures, especially in an agricultural context where achieving sufficient biomass production is crucial. A large diversity is required to face the highly variable and unpredictable summer growing conditions. Complex cover crop mixtures will likely be less productive than bispecific mixtures but will ensure a good performance irrespective of the growing conditions thanks to the sampling effect. This is confirmed by the low risk of failure obtained by the 11species mixture $(20 \%)$.

\subsection{Simplex design methodology}

Simplex design analysis is based on linear models adjusted on a large number of mixtures varying in species proportion and diversity, and results thus mathematically in a highly powerful analysis, without need for replicates. Following the modelling framework developed by Kirwan et al. (2009), the choice of the best fitting model allowed identifying the mechanisms of species interaction and determining the most productive combination. However, the biological interpretation and the application of the results seems limited for cover crops with a short life cycle. Indeed, in some cases, several different models provided a good fit of the data and explained almost the same proportion of biomass variation. These models could however be highly different and resulted thus in very different species composition for the most productive combinations. The assessment of the best model independently for each replicate in 2013 evidenced that, despite very similar growing conditions, the selected model, and thus inferred species interactions, differed highly, ranging from the effect of functional groups only (growing conditions 14 and 15) to a specific interaction linked to mustard and oat (growing condition 13) (Table S5). This highlights that interpretations of the best fitting model should be made with caution and that practical recommendations on the choice of species cannot only be based on one best model. For more accuracy, data should be consolidated, notably by replicating the experiments to reduce data variability. Moreover, as the growing conditions strongly affect the patterns of interaction, it is crucial to investigate contrasting growing conditions to understand the mechanisms involved.

\section{Conclusions}

When growing cover crops, the main objective is to ensure high and stable biomass production so that cover crops provide the expected services. The highly variable growing conditions make this objective hardly achievable using sole crops. Indeed, we observed that sole crop performance depended highly on the growing conditions. Mixtures should thus be chosen rather than sole crops. In most cases, we observed that bispecific mixtures were the most productive thanks to positive pairwise interactions. However, species composition of the most productive mixture varied according to the growing conditions. Even if the benefit of the diversity effect will be lower, it is thus recommended to associate a larger number of species to ensure a good performance of the mixture thanks to the sampling effect. Using a mixture of species with contrasting characteristics will increase the probability to grow species well adapted to the growing conditions but also the probability to benefit from a diversity effect resulting from pairwise interactions. Mixtures with high species diversity ensure a stable and high biomass production with a low risk of failure.

\section{Acknowledgement}

The authors thank Cindy Bally and Nicolas Widmer for the technical work on the experiments, Ursula Steiner for her work on simplex models in cover crops and all the people who helped for the field work. Many thanks also to the two anonimous reviewers who provided relevant comments on a previous version of the manuscript. This study was funded by the Swiss National Science Foundation in the framework of the National Research Program NRP 68 'Sustainable Use of Soil as a Resource' [grant 406840-143063].

\section{Appendix A. Supplementary data}

Supplementary material related to this article can be found, in the online version, at doi:https://doi.org/10.1016/j.agee.2019.04.032. 


\section{References}

Andersen, M.K., Hauggaard-Nielsen, H., Ambus, P., Jensen, E.S., 2004. Biomass production, symbiotic nitrogen fixation and inorganic $\mathrm{N}$ use in dual and tri-component annual intercrops. Plant Soil 266, 273-287. https://doi.org/10.1007/s11104-0050997-1.

Askegaard, M., Eriksen, J., 2007. Growth of legume and nonlegume catch crops and residual-N effects in spring barley on coarse sand. J. Plant Nutr. Soil Sci. 170 (6), 773-780. https://doi.org/10.1002/jpln.200625222.

Barry, K.E., Mommer, L., van Ruijven, J., Wirth, C., Wright, A.J., Bai, Y., Connolly, J., De Deyn, G.B., de Kroon, H., Isbell, F., Milcu, A., Roscher, C., Scherer-Lorenzen, M., Schmid, B., Weigelt, A., 2018. The Future of Complementarity: Disentangling Causes from Consequences. Trends Ecol. Evol. (Amst.). https://doi.org/10.1016/j.tree.2018. 10.013.

Bates, D., Maechler, M., Bolker, B., Walker, S., 2015. Fitting linear mixed-effects models using lme4. J. Stat. Softw. 67 (1), 1-48.

Bedoussac, L., Justes, E., 2010. The efficiency of a durum wheat-winter pea intercrop to improve yield and wheat grain protein concentration depends on $\mathrm{N}$ availability during early growth. Plant Soil 330, 19-35. https://doi.org/10.1007/s11104-0090082-2.

Callaway, R.M., 1998. Are positive interactions speciesspecific? Oikos 82, 202-207. https://doi.org/10.2307/3546931.

Callaway, R.M., Brooker, R.W., Choler, P., Kikvidze, Z., Lortie, C.J., Michalet, R., Paolini, L., Pugnaire, F.I., Newingham, B., Aschehoug, E.T., Armas, C., Kikodze, D., Cook, B.J., 2002. Positive interactions among alpine plants increase with stress. Nature 417, 844-848. https://doi.org/10.1038/nature00812.

Cardinale, B.J., Matulich, K.L., Hooper, D.U., Byrnes, J.E., Duffy, E., Gamfeldt, L., Balvanera, P., O'Connor, M.I., Gonzalez, A., 2011. The functional role of producer diversity in ecosystems. Am. J. Bot. 98, 572-592. https://doi.org/10.3732/ajb. 1000364.

Carnus, T., Finn, J.A., Kirwan, L., Connolly, J., 2015. Assessing the relationship between biodiversity and stability of ecosystem function-is the coefficient of variation always the best metric? Ideas Ecol. Evol. 7, 89-96. https://doi.org/10.4033/iee.2014.7.20.c.

Choler, P., Michalet, R., Callaway, R.M., 2001. Facilitation and competition on gradients in alpine plant communities. Ecology 82, 3295-3308. https://doi.org/10.2307/ 2680153.

Cornell, J.A., 2002. Experiments With Mixtures: Designs, Models, and the Analysis of Mixture Data, third ed. Wiley, New York 680 p.

Crawley, M.J., Brown, S.L., Heard, M.S., Edwards, G.R., 1999. Invasion-resistance in experimental grassland communities: species richness or species identity? Ecol. Lett. 2, 140-148. https://doi.org/10.1046/j.1461-0248.1999.00056.x.

Creissen, H.E., Jorgensen, T.H., Brown, J.K.M., 2016. Increased yield stability of fieldgrown winter barley (Hordeum vulgare L.) varietal mixtures through ecological processes. Crop. Prot. 85, 1-8. https://doi.org/10.1016/j.cropro.2016.03.001.

Díaz, S., Cabido, M., 2001. Vive la difference: plant functional diversity matters to ecosystem processes. Trends Ecol. Evol. (Amst.) 16, 646-655. https://doi.org/10.1016/ S0169-5347(01)02283-2.

Finlay, K.W., Wilkinson, G.N., 1963. The analysis of adaptation in a plant-breeding program. Crop Pasture Sci. 14, 742-754.

Fridley, J.D., 2001. The influence of species diversity on ecosystem productivity: how, where, and why? Oikos 93, 514-526. https://doi.org/10.1034/j.1600-0706.2001. 930318.x.

Gebhard, C.A., Büchi, L., Liebish, F., Sinaj, S., Ramseier, H., Charles, R., 2013. Screening de légumineuses pour couverts végétaux: azote et adventices. Rech Agron Suisse 4, 384-393.

Gfeller, A., Herrera, J.M., Tschuy, F., Wirth, J., 2018. Explanations for Amaranthus retroflexus growth suppression by cover crops. Crop. Prot. 104, 11-20. https://doi.org/ 10.1016/j.cropro.2017.10.006.

Goldberg, D., Novoplansky, A., 1997. On the relative importance of competition in unproductive environments. J. Ecol. 85, 409-418. https://doi.org/10.2307/2960565.

Gravel, D., Bell, T., Barbera, C., Combe, M., Pommier, T., Mouquet, N., 2012. Phylogenetic constraints on ecosystem functioning. Nat. Commun. 3, 1117. https:// doi.org/10.1038/ncomms2123.

Hauggaard-Nielsen, H., Ambus, P., Jensen, E.S., 2001. Interspecific competition, N use and interference with weeds in pea-barley intercropping. Field Crops Res. 70, 101-109. https://doi.org/10.1016/S0378-4290(01)00126-5.

Hauggaard-Nielsen, H., Andersen, M.K., Jørnsgaard, B., Jensen, E.S., 2006. Density and relative frequency effects on competitive interactions and resource use in pea-barley intercrops. Field Crops Res. 95, 256-267. https://doi.org/10.1016/j.fcr.2005.03.003.

Hauggaard-Nielsen, H., Jørnsgaard, B., Kinane, J., Jensen, E.S., 2008. Grain legume-cereal intercropping: the practical application of diversity, competition and facilitation in arable and organic cropping systems. Renew Agric Food Syst. 23, 3-12. https://doi.org/10.1017/S1742170507002025.

Haughey, E., Suter, M., Hofer, D., Hoeckstra, N.J., McElwain, J.N., Lüscher, A., Finn, J.A., 2018. Higher species richness enhances yield stability in intensively managed grasslands with experimental disturbance. Sci. Rep. 8, 15047. https://doi.org/10. 1038/s41598-018-33262-9.

Hayden, Z.D., Ngouajio, M., Brainard, D.C., 2014. Rye-vetch mixture proportion tradeoffs: cover crop productivity, nitrogen accumulation, and weed suppression. Agron. J. 106 (3), 904-914. https://doi.org/10.2134/agronj2013.0467.

Hector, A., Hautier, Y., Saner, P., Wacker, L., Bagchi, R., Joshi, J., Scherer-Lorenzen, M., Spehn, E.M., Bazeley-White, E., Weilenmann, M., Caldeira, M.C., Dimitrakopoulos, P.G., Finn, J.A., Huss-Danell, K., Jumpponen, A., Mulder, C.P.H., Palmborg, C., Pereira, J.S., Siamantziouras, A.S.D., Terry, A.C., Troumbis, A.Y., Schmid, B., Loreau, M., 2010. General stabilizing effects of plant diversity on grassland productivity through population asynchrony and overyielding. Ecology 91, 2213-2220. https:// doi.org/10.1890/09-1162.1.

Hooper, D.U., Chapin, F.S., Ewel, J.J., Hector, A., Inchausti, P., Lavorel, S., Lawton, J.H., Lodge, D.M., Loreau, M., Naeem, S., Schmid, B., Setälä, H., Symstad, A.J., Vandermeer, J., 2005. Effects of biodiversity on ecosystem functioning: a consensus of current knowledge. Ecol. Monogr. 75, 3-35. https://doi.org/10.1890/04-0922.

Husse, S., Huguenin-Elie, O., Buchmann, N., Lüscher, A., 2016. Larger yields of mixtures than monocultures of cultivated grassland species match with asynchrony in shoot growth among species but not with increased light interception. Field Crops Res. 194, 1-11. https://doi.org/10.1016/j.fcr.2016.04.021.

Isbell, F.I., Polley, H.W., Wilsey, B.J., 2009. Biodiversity, productivity and the temporal stability of productivity: patterns and processes. Ecol. Lett. 12, 443-451. https://doi. org/10.1111/j.1461-0248.2009.01299.x.

Isbell, F., Craven, D., Connolly, J., Loreau, M., Schmid, B., Beierkuhnlein, C., Bezemer, T.M., Bonin, C., Bruelheide, H., de Luca, E., Ebeling, A., Griffin, J.N., Guo, Q., Hautier, Y., Hector, A., Jentsch, A., Kreyling, J., Lanta, V., Manning, P., Meyer, S.T., Mori, A.S., Naeem, S., Niklaus, P.A., Polley, H.W., Reich, P.B., Roscher, C., Seabloom, E.W., Smith, M.D., Thakur, M.P., Tilman, D., Tracy, B.F., van der Putten, W.H., van Ruijven, J., Weigelt, A., Weisser, W.W., Wilsey, B., Eisenhauer, N., 2015. Biodiversity increases the resistance of ecosystem productivity to climate extremes. Nature 526, 574-577. https://doi.org/10.1038/nature15374.

Jensen, E.S., 1996. Grain yield, symbiotic N2 fixation and interspecific competition for inorganic N in pea-barley intercrops. Plant Soil 182, 25. https://doi.org/10.1007/ BF00010992.

Jost, L., 2007. Partitioning diversity into independent alpha and beta components. Ecology 88, 2427-2439. https://doi.org/10.1890/06-1736.1.

Kirwan, L., Luscher, A., Sebastia, M.T., Finn, J.A., Collins, R.P., Porqueddu, C., Helgadottir, A., Baadshaug, O.H., Brophy, C., Coran, C., Dalmannsdottir, S., Delgado, I., Elgersma, A., Fothergill, M., Frankow-Lindgerg, B.E., Golinski, P., Grieu, P., Gustavsson, A.M., Hoglind, M., Huguenin-Elie, O., Iliadis, C., Jorgensen, M., Kadziuliene, Z., Karyotis, T., Lunnan, T., Malengier, M., Maltoni, S., Meyer, V., Nyfeler, D., Nykanen-Kurky, P., Parente, J., Smit, H.J., Thumm, U., Connolly, J., 2007. Evenness drives consistent diversity effects in intensive grassland systems across 28 European sites. J. Ecol. 95, 530-539. https://doi.org/10.1111/j.13652745.2007.01225.x.

Kirwan, L., Connolly, J., Finn, J.A., Brophy, C., Lüscher, A., Nyfeler, D., Sebastia, M.T., 2009. Diversity-interaction modeling: estimating contributions of species identities and interactions to ecosystem function. Ecology 90, 2032-2038. https://doi.org/10. 1890/08-1684.1.

Loreau, M., Hector, A., 2001. Partitioning selection and complementarity in biodiversity experiments. Nature 412, 72-76. https://doi.org/10.1038/35083573.

McIntire, E.J., Fajardo, A., 2014. Facilitation as a ubiquitous driver of biodiversity. New Phytol. 201, 403-416. https://doi.org/10.1111/nph.12478.

Miyazawa, K., Takeda, M., Murakami, T., Murayama, T., 2014. Dual and triple intercropping: potential benefits for annual green manure production. Plant Prod. Sci. 17, 194-201. https://doi.org/10.1626/pps.17.194.

Nyfeler, D., Huguenin-Elie, O., Suter, M., Frossard, E., Connolly, J., Lüscher, A., 2009. Strong mixture effects among four species in fertilized agricultural grassland led to persistent and consistent transgressive overyielding. J. Appl. Ecol. 46, 683-691. https://doi.org/10.1111/j.1365-2664.2009.01653.x.

Pugnaire, F.I., Haase, P., Puigdefabregas, J., 1996. Facilitation between higher plant species in a semiarid environment. Ecology 77, 1420-1426. https://doi.org/10. $2307 / 2265539$.

R Core Team, 2018. R: a Language and Environment for Statistical Computing. URL. R Foundation for Statistical Computing, Vienna, Austria. https://www.R-project.org/.

Rees, M., Condit, R., Crawley, M., Pacala, S., Tilman, D., 2001. Long-term studies of vegetation dynamics. Science 293, 650-655. https://doi.org/10.1126/science. 1062586.

Sainju, U.M., Singh, B.P., Whitehead, W.F., Wang, S., 2006. Carbon supply and storage in tilled and nontilled soils as influenced by cover crops and nitrogen fertilization. J. Environ. Qual. 35, 1507-1517. https://doi.org/10.2134/jeq2005.0189.

Sanderson, M.A., 2010. Stability of production and plant species diversity in managed grasslands: a retrospective study. Basic Appl. Ecol. 11, 216-224. https://doi.org/10. 1016/j.baae.2009.08.002.

Sasaki, T., Lu, X., Hirota, M., Bai, Y., 2019. Species asynchrony and response diversity determine multifunctional stability of natural grasslands. J. Ecol. 00, 1-14. https:// doi.org/10.1111/1365-2745.13151.

Schmid, B., Hector, A., Saha, P., Loreau, M., 2008. Biodiversity effects and transgressive overyielding. J. Plant Ecol. 1, 95-102. https://doi.org/10.1093/jpe/rtn011.

Smith, R.G., Atwood, L.W., Warren, N.D., 2014. Increased productivity of a cover crop mixture is not associated with enhanced agroecosystem services. PLoS One. https:// doi.org/10.1371/journal.pone.0097351.

Spehn, E.M., Joshi, J., Schmid, B., Diemer, M., Korner, C., 2000. Above-ground resource use increases with plant species richness in experimental grassland ecosystems. Funct. Ecol. 14, 326-337. https://doi.org/10.1046/j.1365-2435.2000.00437.x.

Steudel, B., Hautier, Y., Hector, A., Kessler, M., 2011. Diverse marsh plant communities are more consistently productive across a range of different environmental conditions through functional complementarity. J. Appl. Ecol. 48, 1117-1124. https://doi.org/ 10.1111/j.1365-2664.2011.01986.x.

Sturludóttir, E., Brophy, C., Bélanger, G., Gustavsson, A.M., Jørgensen, M., Lunnan, T., Helgadóttir, Á., 2014. Benefits of mixing grasses and legumes for herbage yield and nutritive value in Northern Europe and Canada. Grass Forage Sci. 69, 229-240. https://doi.org/10.1111/gfs.12037.

Tilman, D., Knops, J., Wedin, D., Reich, P., Ritchie, M., Siemann, E., 1997. The influence of functional diversity and composition on ecosystem processes. Science 277 , 1300-1302. https://doi.org/10.1126/science.277.5330.1300. 
Tilman, D., Reich, P.B., Knops, J.M.H., 2006. Biodiversity and ecosystem stability in a decade-long grassland experiment. Nature 441, 629-632. https://doi.org/10.1038/ nature 04742 .

Tribouillois, H., Fort, F., Cruz, P., Charles, R., Flores, O., Garnier, E., Justes, E., 2015. A functional characterisation of a wide range of cover crop species: growth and nitrogen acquisition rates, leaf traits and ecological strategies. PLoS One 10, e0122156. https://doi.org/10.1371/journal.pone.0122156.

Tribouillois, H., Cohan, J.P., Justes, E., 2016. Cover crop mixtures including legume produce ecosystem services of nitrate capture and green manuring: assessment combining experimentation and modelling. Plant Soil 401, 347-364. https://doi.org/ 10.1007/s11104-015-2734-8.

Wang, Q., Li, Y., Alva, A., 2012. Cover crops in Mono- and biculture for accumulation of biomass and soil organic carbon. J. Sustain. Agric. 36, 423-439. https://doi.org/10. 1080/10440046.2011.627991.

Wendling, M., Büchi, L., Amossé, C., Sinaj, S., Walter, A., Charles, R., 2016. Influence of root and leaf traits on the uptake of nutrients in cover crops. Plant Soil 409, 419-434. https://doi.org/10.1007/s11104-016-2974-2.

Wendling, M., Büchi, L., Amossé, C., Jeangros, B., Walter, A., Charles, R., 2017. Specific interactions leading to transgressive overyielding in cover crop mixtures. Agric. Ecosyst. Environ. 241, 88-99. https://doi.org/10.1016/j.agee.2017.03.003.

Wortman, S.E., Francis, C.A., Lindquist, J.L., 2012. Cover crop mixtures for the western Corn Belt: opportunities for increased productivity and stability. Agron. J. 104, 699. https://doi.org/10.2134/agronj2011.0422.

Xiao, J., Yin, X., Ren, J., Zhang, M., Tang, L., Zheng, Y., 2018. Complementation drives higher growth rate and yield of wheat and saves nitrogen fertilizer in wheat and faba bean intercropping. Field Crops Res. 221, 119-129. https://doi.org/10.1016/j.fcr. 2017.12.009.

Yachi, S., Loreau, M., 1999. Biodiversity and ecosystem productivity in a fluctuating environment: the insurance hypothesis. Proc Natl Acad Sci. 96, 1463-1468. https:// doi.org/10.1073/pnas.96.4.1463. 